\title{
Navigating the complexity of ecological stability
}

Ian Donohue ${ }^{1,2}$, Helmut Hillebrand ${ }^{3}$, José M. Montoya ${ }^{4}$, Owen L. Petchey ${ }^{5}$, Stuart L. PIMM $^{6}$, Mike S. FOWLER ${ }^{7}$, KeVIN HEALY ${ }^{1,2}$, ANDREW L. JACKSON ${ }^{1,2}$, Miguel LuRGi ${ }^{8}$, DeIRDRE MCClEAN $^{1,2}$, NeSSA E. O'CONNOR ${ }^{9}$, EOIN J. O'GORMAN ${ }^{10}$ \& QIANG YANG ${ }^{1,2}$

${ }^{1}$ School of Natural Sciences, Trinity College Dublin, Ireland

${ }^{2}$ Trinity Centre for Biodiversity Research, Trinity College Dublin, Ireland

${ }^{3}$ Institute for Chemistry and Biology of the Marine Environment, Carl von Ossietzky University Oldenburg, Germany

${ }^{4}$ Theoretical and Experimental Ecological Station, CNRS, UPS, Moulis, France

${ }^{5}$ Institute of Evolutionary Biology and Environmental Studies, University of Zurich, Zurich, Switzerland

${ }^{6}$ Nicholas School of the Environment, Duke University, Durham, USA

${ }^{7}$ Department of Biosciences, Swansea University, UK

${ }^{8}$ Environment Institute and School of Biological Sciences, University of Adelaide, Adelaide, Australia

${ }^{9}$ School of Biological Sciences, Queen's University Belfast, Northern Ireland

${ }^{10}$ Faculty of Natural Sciences, Department of Life Sciences, Imperial College London, UK

Author emails: ID: ian.donohue@tcd.ie; HH: helmut.hillebrand@uni-oldenburg.de; JMM:

Josemaria.MONTOYATERAN@sete.cnrs.fr; OLP: owen.petchey@ieu.uzh.ch; SLP:

stuartpimm@me.com; MSF: m.s.fowler@swansea.ac.uk; KH: HEALYKE@tcd.ie; ALJ:

JACKSOAN@tcd.ie; ML:m.lurgi@creaf.uab.es; DM: MCCLEADM@tcd.ie; NOC:

n.oconnor@qub.ac.uk; EOG: e.ogorman@imperial.ac.uk; QY: QYANG@tcd.ie.

Running head: Navigating the complexity of stability

Keywords: sustainability, disturbance, conservation, policy, resistance, resilience, variability, persistence, invasion, extinction

Type of article: Reviews and Syntheses

Word count: 192 (abstract), 5674 (main text); with four figures, two tables and two text boxes (comprising, respectively, 480 and 356 words).

Number of references: 94

Corresponding Author: $\quad$ Ian Donohue, School of Natural Sciences, Zoology Building, Trinity College, Dublin 2, Ireland. Email: ian.donohue@tcd.ie. Telephone: +35318961356 . Fax: +35316778094 .

Author contributions: ID led the project. ID, SLP, JMM, HH and OLP led the writing. ID, DM, QY and OLP analysed the data. All authors contributed to idea development and the writing of the manuscript. 
1 Abstract

2 Human actions challenge nature in many ways. Ecological responses are ineluctably complex,

3 demanding measures that describe them succinctly. Collectively, these measures encapsulate the

4 overall "stability" of the system. Many international bodies, including the Intergovernmental

5 Science-Policy Platform on Biodiversity and Ecosystem Services (IPBES), broadly aspire to

6 maintain or enhance ecological stability. Such bodies frequently use terms pertaining to stability

7 that lack clear definition. Consequently, we cannot measure them and so they disconnect from a

8 large body of theoretical and empirical understanding. We assess the scientific and policy literature

9 and show that this disconnect is one consequence of an inconsistent and one-dimensional approach

10 that ecologists have taken to both disturbances and stability. This has led to confused

11 communication of the nature of stability and the level of our insight into it. Disturbances and

12 stability are multidimensional. Our understanding of them is not. We have a remarkably poor

13 understanding of the impacts on stability of the characteristics that define many, perhaps all, of the

14 most important elements of global change. We provide recommendations for theoreticians,

15 empiricists and policymakers on how to better integrate the multidimensional nature of ecological

16 stability into their research, policies and actions. 


\section{Introduction}

Species live in a web of prey and other resources, mutualists, competitors, predators, diseases, and other enemies (Montoya et al. 2006; Bascompte 2009; McCann \& Rooney 2009; Kéfi et al. 2012; Tilman et al. 2012). All encounter a profusion of diverse perturbations in their environment, both natural and human-induced, that vary in their spatial extents, periods, durations, frequencies and intensities (Tylianakis et al. 2008; Miller et al. 2011; Pincebourde et al. 2012; MacDougall et al. 2013). These multifaceted disturbances precipitate a range of responses that can alter the many components of ecological stability and the relationships among them (Donohue et al. 2013). This complexity necessitates a multidimensional approach to the measurement of stability. We examine the extent of our understanding of the multidimensional nature of both disturbances and stability. We find that it is highly restricted. Consequently, our ability to maintain the overall stability of ecosystems for different management and policy goals is limited. If ecology is to support and inform robust and successful policy, we must rectify this.

At least three scientific communities use terms that map onto various dimensions of ecological stability. Theoreticians, for example, have developed an extensive literature on whether the population dynamics of multi-species systems will be asymptotically stable in the strict mathematical sense (May 1972; Thébault \& Fontaine 2010; Allesina \& Tang 2012; Rohr et al. 2014), or resilient, in the sense of a fast return to equilibrium following a small disturbance (Pimm \& Lawton 1977; Okuyama \& Holland 2008; Suweis et al. 2013), and other well-defined measures (see, for example, Pimm 1984; McCann 2000; Ives \& Carpenter 2007). Empiricists observe and manipulate natural systems or variously perturb experimental ones to measure ecological responses in constant or naturally changing environments (Tilman et al. 2006; O'Gorman \& Emmerson 2009; Grman et al. 2010; Carpenter et al. 2011; de Mazancourt et al. 2013; O’Connor \& Donohue 2013; Hautier et al. 2014). Finally, many international bodies concerned with environmental conservation aspire to maintain, protect, and sustain nature and avoid altering and degrading it, all for informing 
decision makers and aspiring to enrich people's lives and well-being (Mace 2014; Díaz et al. 2015; Lu et al. 2015).

We explore whether the associated three scientific literatures engage each other in using the same terms and employ the same meanings for them when they do. Generally, they do not. We must remedy this. International bodies need terms that are simple and flexible, but surely not to the point of being meaningless. Theory cannot advance usefully in isolation from tests of it (Scheiner 2013), and theory, experiment, and observation must sensibly inform decision makers at all levels. Most importantly, the multidimensional complexity of natural responses to environmental change needs to be recognised by all communities, both separately and collectively.

We suggest solutions to help achieve these goals. For theoreticians, we provide suggestions on where to focus future research to incorporate the sort of complexities commonly encountered in natural systems. Empiricists will find useful our summary of the methodologies developed so far to study the different facets of ecological stability and our recommendations for better assessing stability in collaboration with theoreticians and policymakers. Finally, we provide suggestions for environmental policymakers on how to develop and frame objectives and targets that are not only relevant for policy but at the same time facilitate much closer links with the supporting, and evolving, science.

\section{The multifaceted nature of disturbances and ecological responses}

Disturbances are changes in the biotic or abiotic environment that alter the structure and dynamics of ecosystems. Although they occur at a variety of scales and vary in their direct and indirect effects on species, all disturbances comprise four key properties; their magnitude, their duration, their frequency and how they change over space and time (Sousa 1984; Benedetti-Cecchi 2003; García Molinos \& Donohue 2011; Pincebourde et al. 2012; Tamburello et al. 2013). The magnitude of a disturbance is defined by how much the aspect of environmental change departs from its undisturbed state (i.e. "a measure of the strength of the disturbing force"; Sousa 1984). A 
minor storm versus a once in 100-year hurricane is an example of disturbances that vary in magnitude. Their duration refers to a continuum with instantaneous pulses - short, sharp shocks - and sustained presses — constant, long-term change — at the ends of the spectrum (Fig. 1a). A discrete pollution event, such as a chemical spill, is a pulse, and the extinction of a species from an ecosystem is a press. Theoreticians focus primarily on one of these two extremes of the duration gradient (Ives \& Carpenter 2007). Empiricists sometimes refer to these extremes as acute and chronic disturbances, respectively.

Natural disturbance regimes are clearly more complicated than this. Changes in the magnitude, duration and frequency of disturbances over time or in space can combine to give disturbances directionality (Fig. 1b). Directionality measures the trajectory of change, which can be highly dynamic and variable in terms of its mean and variance. Both can elicit distinct ecological responses (Bertocci et al. 2005; Benedetti-Cecchi et al. 2006; García Molinos \& Donohue 2010, 2011; Pincebourde et al. 2012; Mrowicki et al. 2016). Many of the most globally important disturbances in nature are of this kind (Fig. 1c). Therefore, while a focus on pure pulse or press disturbances provides some important insight into mechanisms that can underpin biological responses to disturbances, the relevance of this to predicting responses to real disturbances in the natural world may be limited.

While the multifaceted nature of disturbances creates a problem for assessing, understanding, and predicting how ecological systems respond (García Molinos \& Donohue, 2010; Mrowicki et al. 2016), the ecological responses themselves are also complex. Ecological stability is a multidimensional concept that tries to capture the different aspects of the dynamics of the system and its response to perturbations. Pimm (1984) reviewed five components of ecological stability that are in common use. Asymptotic stability is a binary measure describing whether a system returns asymptotically to its equilibrium following small disturbances away from it. One measures variability, the inverse of stability, as the coefficient of variation of a variable over time or across space. Persistence is the length of time a system maintains the same state before it changes in some 
defined way. It is often used as a measure of the susceptibility of systems to invasion by new species or the loss of native species. Resistance is a dimensionless ratio of some system variable measured after, compared to before, some perturbation. Resilience is the rate at which a system returns to its equilibrium, often measured as its reciprocal, the return time for the disturbance to decay to some specific fraction of its initial value. Systems with shorter (faster) return times are more resilient than those that recover more slowly. Holling (1973) introduced another definition of resilience that is currently in common use, particularly in policy fora (Walker et al. 2004; Hodgson et al. 2015). It "is a measure of the persistence of systems and of their ability to absorb change and disturbance and still maintain the same relationships between populations or state variables." This definition is multidimensional. It integrates persistence, resistance and the existence of local asymptotic stability at multiple equilibria. It has come to mean whether or not a system returns to its former equilibrium following disturbance or moves to another one. This idea may be expanded further to compare systems in terms of what range of disturbances a system can withstand before being shifted to a new equilibrium (Ives \& Carpenter 2007). If there is a limit beyond which a system cannot return directly to its former state, this is termed a tipping point.

The different components of stability are all based in some way on the composition, function and dynamics of communities. They are unlikely to be independent. Furthermore, the strength and even the nature of relationships among stability components can change when communities are disturbed in different ways (Donohue et al. 2013). This complexity has critical implications for our understanding of the impacts of disturbances on ecosystems. It means that restricting our focus to single measures of stability in isolation, or to amalgamated ones such as Holling's resilience, when they are used to reduce the multidimensional complexity of stability to a single dimension and its measurement to a single number, risks significantly underestimating the impacts of perturbations. It also risks incomplete understanding of the mechanisms that underpin the overall stability of ecosystems. The multidimensionality of ecological responses demands explicit multidimensional measurement of both disturbances and stability. 
The definitions of the various components of stability all come with underlying assumptions

121 about the nature of ecosystems and the disturbances that affect them. Measures of variability, for example, commonly assume the presence of stationary fluctuations [i.e. without an underlying directional trend (Tilman et al. 2006; Loreau \& de Mazancourt 2013)]. The ecological definitions of resilience (Quinlan et al. 2016) argue for different worldviews, one where a single equilibrium dominates, the other where two or more equilibrium domains are possible, with tipping points 126 between them. The Aichi Targets (UN 2010) that consider "safe ecological limits" may invoke the latter view, as do related concepts, such as planetary boundaries, that are the subject of considerable debate (Box 1). Other definitions may read into a simpler notion of, for example, preventing overexploitation. Irrespective of definitions, theoretical studies of stability are generally based on the dynamics of communities at, or very close to, some form of equilibrial state. Given the highly dynamic nature of the natural world and the strong directionality of many elements of global change, this limits the applicability of existing theory to the real world and creates significant challenges for empiricists trying to test its predictions.

\section{What do ecologists measure?}

To understand the differences in what theoreticians and empiricists study, we surveyed three high impact multidisciplinary journals and four leading general ecology journals: Nature, Science, PNAS, Ecology Letters, Ecology, Oikos and American Naturalist. Using relevant search terms (“ecolog* stability"; "ecolog* resilience"; "ecolog* resistance"; "stability and diversity”), this yielded 894 papers, 354 of which measured ecological stability in one or more ways. About half of these studies were purely theoretical, the other half empirical. Of the latter, there were nearly equal proportions of experimental and observational studies. Only 4\% of papers combined both theory and empirical measurement. 

experimental and observational studies also focus on only a single disturbance component (Fig. 2b).

This demonstrates a restricted, largely one-dimensional, perspective. It means that we have little understanding of either the multidimensional nature of ecological stability or the correspondence of different components of stability to different types of perturbations.

There is also a significant disjoint between theoretical and empirical approaches to, and understanding of, ecological stability. The majority (57\%) of theoretical studies focus on asymptotic stability, whereas experimental (61\%) and observational (72\%) studies concentrate primarily on variability (Fig. 3a). In contrast, asymptotic stability comprises the focus of only $4 \%$ of empirical studies, while only $18 \%$ of theoretical studies quantified variability. Only a small minority of studies, either theoretical or empirical, examine persistence ( $10 \%$ of studies), resilience $(7 \%)$ or resistance $(7 \%)$. Within these latter three measures, there are notable differences.

Theoretical studies most often examine persistence, resilience and a particular measure of resistance called robustness - the susceptibility to species extinctions, usually caused by the initial loss of a species (Solé \& Montoya 2001; Staniczenko et al. 2010). Observational studies emphasise resistance, while experimental studies consider resistance and resilience in equal measure. Our survey identified very few empirical studies of robustness. Additional aspects of stability are potentially addressed in more specialized journals than those scanned in our survey. However, the literature we surveyed came from the general ecological journals most probably read by both theoreticians and empiricists, potentially making the divergence we found in terms and concepts even more significant.

We found similar disparities between the focus of theory and empirical research on the different types of disturbance durations and frequencies. The majority $(70 \%)$ of theoretical studies focus on the effects of single pulse perturbations on stability (Fig. 3b). In contrast, $83 \%$ of observational studies examine the effects of combined, multiple pulse disturbances (Fig. 1a), usually in the form of natural environmental fluctuations. Experimental studies prioritise the effects of press and multiple pulse disturbances in broadly equal measure (respectively, $38 \%$ and $47 \%$ ). 
172 Only $15 \%$ of studies we surveyed incorporate the effects of disturbance magnitude. The problem is 173 more acute when we account for different components of stability. For example, our survey 174 identified no theoretical studies of the effects of disturbance magnitude, pulse or multiple pulse disturbance frequencies on ecological resistance. Nor did we find any experimental or observational studies of the effects of pulse disturbances on asymptotic stability (Fig. S1). In spite of its importance to characterising disturbances in the real world, our survey identified only one study (van Nes \& Scheffer 2004) that explored the effects of the directionality of a disturbance on ecological stability.

Almost exclusively, just two characteristics of communities provide the basis upon which studies measure ecological stability. Population or community biomass comprises the focus of approximately two-thirds (63\%) of studies included in our survey, while almost all of the remaining studies $(35 \%)$ examine the stability of taxonomic composition in some way (Fig. 3c). This pattern is broadly consistent across both theoretical and empirical studies and across all components of stability, except for persistence, where the majority of studies focus on composition, and robustness, whose definition is constrained to community composition (Fig. S2). We found few 187 (six) studies that measured the resilience of community composition. In spite of the strong policy focus on ensuring the sustained provision of ecosystem services (e.g. TEEB 2010; Díaz et al. 2015), we found remarkably few empirical or theoretical assessments of the stability of related ecosystem functions or processes. Only $2 \%$ of studies in our survey examined the stability of an ecosystem function or process, in spite of their importance to the perceived economic value of ecosystems (Armsworth \& Roughgarden 2003). Of those, almost all measured the variability of ecosystem function in time or space. We found only one study (Zavaleta et al. 2010) that also examined thresholds for the persistence of multiple functions. Our survey identified no studies of the resilience, asymptotic stability or resistance of ecosystem functions. There is significant bias towards terrestrial ecosystems (52\%) among empirical studies of 197 stability, of which most (53\%) are from grasslands. Of the remaining studies, $29 \%$ are from 
198 freshwater ecosystems, while only $16 \%$ are from marine systems. Experimental and observational

199 studies are represented approximately equally across all ecosystem types.

What are the conclusions we draw from this? Clearly, experimentalists and empiricists can

201 estimate the clearly-defined measures used by theoreticians. The problem is that some things are

202 easy to measure and other things not, a distinction that likely leads to the differences we have noted.

203 The differences are even greater on closer inspection: theory does not always address what

204 empiricists can measure. This is, at least in part, because the mathematics of dynamical systems

205 lacks tools for evaluating quantities of interest to empirical ecologists. Take resilience, for example.

206 Models measuring resilience use the engagingly simple idea of asymptotic stability. They calculate

207 return times over long intervals — when transient changes have decayed — and close to the

208 equilibrium - where one can use linear approximations to the underlying non-linear nature of the

209 system (Pimm 1982). Empiricists, on the other hand, tend to look at short intervals and disturbances

210 far from the equilibrium, where transient effects in the models may be significant (De Vries et al.

211 2012; Hoover et al. 2014; O’Connor et al. 2015). Here, the simplifying mathematics are

212 unavailable, and so are ignored. The models may still provide broadly the right insights, but there is

213 no guarantee that they do. Theoreticians could take the extra step and explore the dynamics of their

214 models over short intervals away from equilibrium, even if only using simulations, to check their

215 generality (e.g. Hastings 2004; Ives \& Carpenter 2007; Ruokolainen \& Fowler 2008). More

216 generally, theoreticians might recognise that certain aspects of their theories are far more likely to

217 be tested - and to be more widely useful — if they addressed metrics that empiricists can more

218 easily measure (Shou et al. 2015).

219 A more fundamental problem arises from the lack of exploration of the multidimensional 220 nature of either disturbances or stability. This gap in knowledge limits our ability to understand and 221 predict the effects of disturbances on the overall stability of ecosystems. If the science of ecology is 222 to support and inform robust and successful policy, we should close this gap. 


\section{The goals of policy and their measurement}

Many consequences of human actions on nature are simple and have clearly defined units. For instance, the United Nations Convention on Biological Diversity (CBD) and related conventions sets targets that include the numbers of species and areas of habitat to be protected, and rates of extinction, habitat loss and fragmentation, and overexploitation of fisheries and rangelands to be minimised (UN 1992). Assisting developing countries reduce carbon emissions from deforestation and forest degradation is the simply stated goal of the United Nations REDD (Reducing Emissions from Deforestation and Forest Degradation in Developing Countries) Programme (UN 2008). These may neither be easy to measure in practice nor to manage effectively, but they do not pose conceptual challenges.

Much more problematic are associated terms. Sustainability is ubiquitous (Bosch et al. 2015), and has a large associated literature. For some, it is used in a normative way, that is, as some desired goal or set of goals. Thus, it is part of the mission of the Global Environment Facility (GEF), and about half of the CBD's Aichi Biodiversity Targets for 2010-2020 include the word (UN 2010). IPBES includes conservation and sustainability of ecosystem services to provide longterm human well-being in its conceptual framework (Díaz et al. 2015). Responsibilities of the UK Department for Environment, Food and Rural Affairs include sustainable development, which China adopted explicitly as a national strategy in 1996 (Chinese Ministry of Finance et al. 2014). Most commercial enterprises now include statements about corporate and environmental sustainability in their mission statements. Normative definitions of sustainability therefore play an important role in policy, and environmental decision makers clearly do not only concern themselves with ecological components of stability. But neither should they ignore them.

We defer to the Oxford English Dictionary that defines "sustainable" as "the quality of being sustainable at a certain rate or level" and environmentally sustainable as "the degree to which a process or enterprise is able to be maintained or continued while avoiding the long-term depletion of natural resources." Following this, we take sustainability (in its non-normative sense) to mean 
that a particular resource persists, or persists above (or below) some pre-determined level, or is resistant to disturbances. Its translation to ecological concepts is conceptually straightforward. Other terms are less so. For example, the 20 Aichi Targets include: safe ecological limits (Targets 4 \& 6), degradation (Target 5), function (Targets 8, $10 \& 19$ ), and integrity (Target 10) (UN 2010). These terms lack definitions, or have more than one definition, and have no clear units for quantification. This imprecision is unfortunate in itself (Bosch et al. 2015; Lu et al. 2015). It also denies the integration of the large body of empirical and theoretical literature that deals with broadly similar, but quantifiable, measures of multi-species systems that might provide key insights.

Differences among terms used, and in the meanings of common terms (Grimm et al. 1992; Grimm \& Wissel 1997; Ives \& Carpenter 2007; Hodgson et al. 2015), are likely a consequence of the different goals of theoretical and empirical ecologists and policymakers and practitioners. They also reflect the fact that ecologists have perhaps less influence on these terms and their use than we might hope. These differences create significant challenges for translating research findings into policy-relevant information, for communication among individuals from different groups, and for dealing with the complexity and multifaceted nature of ecological stability. We now examine the terms used by policymakers and practitioners, then explore the potential for common ground.

\section{How do ecologists and policymakers differ in the terms they use?}

We surveyed policy targets and mission and vision statements of 42 key international agreements, organisations and agencies (Table 1) that are concerned primarily with the conservation and protection of nature. We searched for terms that are associated positively with stability. The most common terms we found were, by some distance, 'sustain' and 'sustainability'. These were present in more than half of the targets and statements examined (Table 2). They occurred almost twice as frequently as the next most common terms, 'conserve' and 'conservation'. We identified 14 other terms that occurred less frequently across the documents we examined (Table 2). Of all of 
the terms we identified, only two, 'stabilise'/'stable' and 'resilience'/'resilient', have clear ecological definitions. Unfortunately, their use in the documents implied different meanings to those widely used in ecological theory, relating most strongly to, respectively, variability and resistance.

In spite of the widely different terminologies used by ecologists and policymakers and practitioners, all of the terms we identified in policy targets and statements could be associated in some way with at least one, and frequently more than one, component of ecological stability (Table 2). In fact, the stability components that associate most strongly with these terms are among the least studied by ecologists (Fig. 3a). For some terms, the link with components of stability was clear, for others less so. For example, to 'constrain impacts' necessitates increasing the resistance of systems to disturbances. It also implies increasing their resilience (i.e. reducing their return times). The fact that the majority of the terms used in policy integrate across different components of ecological stability means that they are also, at least implicitly, multifaceted. 'Sustainable' is a good example of this. In order to be sustainable, ecosystems must be resistant to disturbances. They must recover quickly from them (i.e. have high resilience). This implies that at least some properties (e.g. primary production) remain relatively unchanged through time (i.e. have high robustness, low variability) even though there may be considerable turnover in other properties (e.g. species composition; indeed, it may be the turnover in species composition that results in sustainable primary production).

Thus, key terms may lack unambiguous and clear definitions, and are not therefore directly quantifiable. Yet, the widespread use of such holistic terms implies that the multidimensionality of ecological stability is already integrated, even if unconsciously, in the language and targets of policymakers. This observation provides the motivation for closer integration with the science of ecology.

\section{Solutions and recommendations}


Nature responds to human pressures in complex ways. Conversely, political and governance

303 decisions often demand simplicity (OECD 2001; Harwood \& Stokes 2003; Lu et al. 2015).

304 Acknowledging this dilemma is a first step towards enhancing the quality of the communication of 305 "stability" at the science-policy interface and within both science and policy. It is incumbent upon 306 ecologists to ensure that this process does not dilute the integrity of the underlying science.

The necessary second step involves the definition of terms and their measurement. There is a

309 to attach measurable quantities to the terms used in their documents, while scientists must address

310 these concepts directly in their studies. The proliferation of undefined and, indeed, unmeasurable

311 ideals, such as many of the tasks that underpin the recently published United Nations Sustainable

312 Development Goals (SDGs) for the conservation of ecosystems (Goals 14 and 15), hinders progress

313 and is self-defeating. For example, SDG Task 14.2 sets the target that, "By 2020, (countries will)

314 sustainably manage and protect marine and coastal ecosystems and avoid significant adverse

315 impacts, including by strengthening their resilience". This statement is ambiguous to the point of

316 being meaningless. Not a single aspect of this target is measurable. What constitutes "significant"?

317 What does resilience mean in this context? The goals of policy and the terminology used to describe 318 them always need to be defined and measurable.

319 Consider two examples from the Aichi Targets that contrast how measureable are their 320 aspirations. First, Aichi Target 11: “By 2020, at least 17 per cent of terrestrial and inland water, 321 and 10 per cent of coastal and marine areas... are conserved through effectively and equitably 322 managed, ecologically representative and well connected systems of protected areas". These goals 323 are explicit and measureable, but those for Aichi Target 6 are not: "By 2020 all fish and 324 invertebrate stocks and aquatic plants are managed and harvested sustainably...so that ... fisheries 325 have no significant adverse impacts on threatened species and vulnerable ecosystems and the 326 impacts of fisheries on stocks, species and ecosystems are within safe ecological limits". This 327 statement contains three particularly obscure terms that lack clear methods for measurement - 
sustainably, significant adverse impacts and safe ecological limits - each of which appears to mean two distinct things. As used in this context (see also Table 2), sustainably has a compositional aspect - that species present in the system persist - and another related to biomass stability - that variability of biomass at both population and community level is minimised at least to a level that ensures the persistence of species. Significant adverse impacts requires that the persistence of both 'threatened species' and the functioning of 'vulnerable ecosystems' is ensured, while safe ecological limits requires ensuring the persistence of each of the biomass, composition and functioning of ecosystems, presumably by enhancing their resistance to fishing activities. Removing the obscure terms and replacing them with the clearly defined ones we suggest would make the goal measureable. This would enable closer links with the supporting science and highlight key research needs, which, in turn, make the goal attainable.

For their part, scientists need to take a coherent approach to quantifying stability, such as the one we describe here. The field will not advance by publishing more, partly overlapping, definitions of single terms used in isolation within a discipline. We need to employ broadly accepted terms and apply them consistently across different communities. Both theoreticians and empiricists also need to be more explicit about the basis upon which they are measuring stability. Conclusions drawn about the factors that drive biomass resilience, for example, are likely to be very different from those that underpin compositional resilience.

The third step is crucial. Both scientists and policymakers need to recognise that the multidimensional nature of environmental change always requires a multidimensional assessment of responses. To date, scientists and policymakers alike have tended to assess the response to one driver of change using one aspect of stability or amalgamated concepts such as Holling's resilience. The hope is that this strategy provides a piece of the jigsaw that, in total, provides insight into the overall complexity of responses. Rather, such simplification blurs the overall picture. For example, increasing temporal variability of algal biomass may indicate transient dynamics in changing lake food-webs (Carpenter et al. 2011). It tells us little about any underlying changes in community 
structure that may be undermining, or indeed enhancing, resistance to different kinds of disturbances. The one-dimensional approach to disturbances and stability means that we underestimate the impacts of perturbations and cannot identify the mechanisms that underpin the overall stability of ecosystem structure or functions. The existence of trade-offs (i.e. inverse correlations) between different components of stability exacerbates this situation. Such trade-offs exist in nature (Donohue et al. 2013) and there is some theoretical insight into why they occur (Harrison 1979; Loreau 1994; Dai et al. 2015). Their existence has profound implications for policymakers and practitioners, necessitating decisions on which aspects of stability to prioritise for different management goals. They also provoke an environmental cost to those decisions, where some aspects of ecological stability are necessarily diminished to enhance others. The lack of exploration of the multidimensional nature of ecological stability means that our ability to optimise the overall stability of ecosystems for different management and policy goals is at present extremely limited.

\section{What science is needed to support these steps and enhance the efficacy of policy?}

We make three recommendations. First, the necessity for improved and mechanistic insight into the multidimensional nature of disturbances and stability requires more realistic theory and experimental designs and an improved ability to integrate across studies from different spatial and temporal scales and different kinds of ecosystem (e.g. Peters et al. 2011). Even single pulse disturbances (e.g., a chemical spill) often have a legacy (e.g., contamination, loss of rare species) that corresponds to a press disturbance. Pulse and press disturbances likely affect different components of stability in different ways. Likewise, many press disturbances exhibit clear directionality and dynamic variation around the mean, with single extreme events occurring more frequently. For instance, the nature of climate disruption calls for new theory (Ives et al. 2010; Stenseth et al. 2015) and long-term experiments. These need to consider the incrementally increasing magnitude of, for example, temperature change, and the possibility of including large 
380

variability up to extreme climatic events. They must employ stability metrics that do not require strong equilibrium assumptions (e.g. fixed point attractors). Moreover, they must be able to evaluate ecosystems in continuous transient dynamics (Fukami \& Nakajima 2011). The research of theoretical and empirical ecologists has to include the complex nature of disturbances and stability, and the result of such multidimensional approaches has to inform policymakers.

Some existing theoretical approaches may be extended to deal with this range of natural complexity. For example, Floquet theory can be used to explore the stability properties of periodic (cyclical, non-single point equilibrium) systems (e.g. Lloyd \& Jansen 2004, Klausmeier 2008). This can be developed in a similar way to assess how locally stable, single point equilibria respond to perturbations. Lyapunov exponents can be used to investigate more complex, chaotic intrinsic dynamics in naturally variable systems (Ellner \& Turchin 1995). Gao et al. (2016) have proposed general methods that can reduce the high dimensionality of multi-species systems to predict the loss of resilience (defined there as the ability to avoid switching from a relatively high to much lower mean value of a focal state variable). In parallel, new theoretical developments are starting to explore links between what empiricists measure (e.g. variability) and what theoreticians analyse (e.g. asymptotic resilience), showing that some fundamental relationships can be established (Arnoldi et al. 2016). Together, these approaches offer promising new directions for further theoretical research that incorporate the sort of complexities empiricists commonly encounter in their study systems.

Second, we need simple, yet scientifically sound, ways to integrate across the multiple dimensions to quantify the overall stability of ecosystems. These methods will need to distil the most important elements of stability and make accurate quantitative measures on each dimension. Only then can we combine them (Fig. 4). These methods also need to be adaptable to the priorities of specific policies. Such adaptation is fundamental to optimising the overall stability of ecosystem structure and/or functioning for different management and policy objectives. Agricultural management, for example, aims to minimise variability of yield production and maximise 
resistance of biomass to pathogens and insect pests. In contrast, many conservation programs might

407 try to maximise the compositional persistence and resilience of communities (rare species are often 408 the most endangered and they tend to determine the slowest return times of the system). Such semi409 quantitative methods of holistic assessment may seem too broad-brush and inaccurate to satisfy 410 many scientists. They may also be too complex for some policymakers. The solution has to be 411 something that sits between the two.

412 Third, we need to evaluate and monitor stability through space and time. Ecologists have 413 experience in doing this for single populations and key functional groups (e.g. Ives et al. 2008; 414 Carpenter et al. 2011) and, more recently, for monitoring changes in the provision of ecosystem 415 goods and services (Tallis et al. 2012). Monitoring the dynamic stability of whole networks has 416 largely been the province of economists, among others, with numerous financial stability 417 monitoring programs continuously tracking sources of systemic risk (Adrian et al. 2014). 418 Analogous programs for monitoring the dynamic multidimensional stability of whole ecological 419 systems over time and space are essential to help assess the effectiveness of policy and management 420 actions. These programmes are needed to help identify ecosystems whose stability is being 421 compromised in the face of global change.

\section{Conclusions}

There are policies concerned with the protection of nature that set defined and measurable targets. Aichi Target 5 (UN 2010) constitutes a good exemplar: "By 2020, the rate of loss of all natural habitats, including forests, is (to be) at least halved and where feasible brought close to zero". This statement is clear and unambiguous - progress can be quantified, success or failure evaluated. It exemplifies the only way that policies can effect meaningful change.

Such policies are in the minority. Many policy documents describe targets that may appear,

430 on face value, explicit and measurable, yet contain terms that are ambiguous, or have multiple 431 definitions that mean different things to different people. Such targets cannot be connected to 
measureable ecological processes or properties. Policies aiming to increase "resilience" provide pervasive examples. In fact, the majority of policy documents we surveyed contain goals using terms that lack definition within ecology. Such ambiguity paralyses policy.

This incoherence is, at least in part, a consequence of the inconsistent and one-dimensional approach that ecologists have taken to ecological stability. This approach has led to confused communication of the nature of stability and the level of our insight into it. Disturbances and stability are multidimensional. Our understanding of them is not. We have a remarkably poor understanding of the impacts on stability of the characteristics that define many, perhaps all, of the most important elements of global change.

The solution requires a range of actions. We need more realistic theory based on measures that are of practical significance and empirically quantifiable. Empiricists need to test this theory at a range of spatial and temporal scales. Policymakers need to use these defined and measurable quantities in their targets. Most importantly, theoreticians, empiricists, policymakers and practitioners each need to incorporate the multidimensional complexity of natural responses to environmental change into their research, policies and actions.

\section{Acknowledgements}

A UK NERC/BESS Tansley Working Group award supported this study. We thank Stefano Allesina, David Raffaelli and an anonymous reviewer for their insightful comments, which helped to improve the quality of this manuscript. DM was funded by a Postgraduate Award from Trinity College Dublin. QY was funded by a postgraduate scholarship from the Irish Research Council. KH was funded by the Earth and Natural Sciences (ENS) Doctoral Studies Programme, funded by the Higher Education Authority (HEA) through the Programme for Research at Third Level Institutions, Cycle 5 (PRTLI-5), co-funded by the European Regional Development Fund (ERDF). OLP was supported by SNF project 31003A_159498 and the University of Zurich Global Change and Biodiversity Research Priority Programme. $\mathrm{HH}$ received funding from the German Science 
458 Foundation (DFG Hi848 18-1). JMM was supported by the French Laboratory of Excellence

459 Project “TULIP” (ANR-10-LABX-41; ANR-11-IDEX-0002-02).

460

$461 \quad$ References

4621.

463 Adrian, T., Covitz, D. \& Liang, N. (2014). Financial stability monitoring, Staff Report No. 601, 464 Federal Reserve Bank of New York.

4652.

466 Allesina, S. \& Tang, S. (2012). Stability criteria for complex ecosystems. Nature, 483, 205-208.

4673.

468 Armsworth, P. R. \& Roughgarden, J. E. (2003). The economic value of ecological stability. Proc.

469 Natl. Acad. Sci. U.S.A., 100, 7147-7151.

4704.

471 Arnoldi, J.-F., Loreau, M. \& Haegeman, B. (2016). Resilience, reactivity and variability: A

472 mathematical comparison of ecological stability measures. J. Theor. Biol., 89, 47-59.

4735.

474 Bascompte, J. (2009). Disentangling the web of life. Science, 325, 416-419.

4756.

476 Benedetti-Cecchi, L. (2003). The importance of the variance around the mean effect size of

477 ecological processes. Ecology, 84, 2335-2346.

4787.

479 Benedetti-Cecchi, L., Bertocci, I., Vaselli, S. \& Maggi, E. (2006) Temporal variance reverses the

480 impact of high mean intensity of stress in climate change experiments. Ecology, 87, 2489-2499.

4818.

482 Bertocci, I., Maggi, E., Vaselli, S. \& Benedetti-Cecchi, L. (2005). Contrasting effects of mean

483 intensity and temporal variation of disturbance on a rocky seashore. Ecology, 86, 2061-2067. 
4849.

485 Bosch, R., van de Pol, M. \& Philp, J. (2015). Define biomass sustainability. Nature, 523, 526-527. 48610.

487 Byrnes, J. E. K., Gamfeldt, L., Isbell, F., Lefcheck, J. S., Griffin, J. N., Hector, A. et al. (2014). 488 Investigating the relationship between biodiversity and ecosystem multifunctionality: challenges 489 and solutions. Methods Ecol. Evol., 5, 111-124.

$490 \quad 11$.

491 Cardinale, B. J., Matulich, K. L., Hooper, D. U., Byrnes, J. E., Duffy, E., Gamfeldt, L. et al. (2011). 492 The functional role of producer diversity in ecosystems. Am. J. Bot., 98, 572-592.

49312.

494 Cardinale, B. J., Duffy, J. E., Gonzalez, A., Hooper, D. U., Perrings, C., Venail, P. et al. (2012). 495 Biodiversity loss and its impact on humanity. Nature, 486, 59-67.

49613.

497 Carpenter, S. R., Cole, J. J., Pace, M. L., Batt, R., Brock, W. A., Cline, T. et al. (2011). Early 498 warnings of regime shifts: a whole-ecosystem experiment. Science, 332, 1079-1082. 49914.

500 Chinese Ministry of Finance, Chinese Ministry of Foreign Affairs, Chinese Ministry of Science and 501 Technology, Chinese Ministry of Environmental Protection, Chinese National Development and 502 Reform Commission \& Guo, L. C. (2014). The People's Republic of China National Report on 503 Sustainable Development. ICP Intercultural Press.

50415.

505 Dai, L., Korolev, K. S. \& Gore, J. (2015). Relation between stability and resilience determines the 506 performance of early warning signals under different environmental drivers. Proc. Natl. Acad. Sci. 507 U.S.A., 112, 10056-10061.

50816. 
509 de Mazancourt, C., Isbell, F., Larocque, A., Berendse, F., De Luca, E., Grace, J. B. et al. (2013).

510 Predicting ecosystem stability from community composition and biodiversity. Ecol. Lett., 16, 617-

511625.

51217.

513 De Vos, J. M., Joppa, L. N., Gittleman, J. L., Stephens, P. R. \& Pimm, S. L. (2015). Estimating the 514 normal background rate of species extinction. Conserv. Biol., 29, 452-462.

51518

516 De Vries, F. T., Liiri, M. E., Bjørnlund, L., Bowker, M. A., Christensen, S., Setälä, H. M. et al.

517 (2012). Land use alters the resistance and resilience of soil food webs to drought. Nature Clim.

518 Change, 2, 276-280.

51919.

520 Díaz, S., Demissew, S., Carabias, J., Joly, C., Lonsdale, M., Ash, N. et al. (2015). The IPBES

521 Conceptual Framework—connecting nature and people. Curr. Opin. Environ. Sustain., 14, 1-16. 52220.

523 Donohue, I., Petchey, O. L., Montoya, J. M., Jackson, A. L., McNally, L., Viana, M. et al. (2013).

524 On the dimensionality of ecological stability. Ecol. Lett., 16, 421-429.

52521.

526 Ellner, S. \& Turchin, P. (1995). Chaos in a noisy world: new methods and evidence from time-

527 series analysis. Am. Nat., 145, 343-375.

52822.

529 Fukami, T. \& Nakajima, M. (2011). Community assembly: alternative stable states or alternative $530 \quad$ transient states? Ecol. Lett., 14, 973-984.

53123

532 Gao, J., Barzel, B. \& Barabási, A.-L. (2016). Universal resilience patterns in complex networks.

533 Nature, 530, 307-312.

53424. 
535 García Molinos, J. \& Donohue, I. (2010). Interactions among temporal patterns determine the

536 effects of multiple stressors. Ecol. Appl., 20, 1794-1800.

53725.

538 García Molinos, J. \& Donohue, I. (2011). Temporal variability within disturbance events regulates

539 their effects on natural communities. Oecol., 166, 795-806.

54026.

541 Grimm, V. \& Wissel, C. (1997). Babel, or the ecological stability discussions: An inventory and 542 analysis of terminology and a guide for avoiding confusion. Oecol., 109, 323-334.

54327.

544 Grimm, V., Schmidt, E. \& Wissel, C. (1992). On the application of stability concepts in ecology.

545 Ecol. Model., 63, 143-161.

54628.

547 Grman, E., Lau, J. A., Schoolmaster, D. R. \& Gross, K. L. (2010). Mechanisms contributing to

548 stability in ecosystem function depend on the environmental context. Ecol. Lett., 13, 1400-1410.

54929.

550 Harrison, G. W. (1979). Stability under environmental stress: resistance, resilience, persistence and 551 variability. Am. Nat., 113, 659-669.

55230.

553 Harwood, J. \& Stokes, K. (2003). Coping with uncertainty in ecological advice: lessons from

554 fisheries. Trends. Ecol. Evol., 18, 617-622.

55531.

556 Hastings, A. (2004). Transients: the key to long-term ecological understanding? Trends. Ecol. Evol., $557 \quad 19,39-45$.

$558 \quad 32$. 
559 Hautier, Y., Seabloom, E. W., Borer, E. T., Adler, P. B., Harpole, W. S., Hillebrand, H. et al.

560 (2014). Eutrophication weakens stabilizing effects of diversity in natural grasslands. Nature, 508,

$561 \quad 521-525$.

56233.

563 Hodgson, D., McDonald, J. L. \& Hosken, D. J. (2015). What do you mean, 'resilient'? Trends Ecol. 564 Evol., 30, 503-506.

56534.

566 Holling, C. S. (1973). Resilience and stability of ecological systems. Annu. Rev. Ecol. Evol. Syst., 4, $567 \quad 1-23$

$568 \quad 35$

569 Hoover, D. L., Knapp, A. K. \& Smith, M. D. (2014). Resistance and resilience of a grassland

570 ecosystem to climate extremes. Ecology, 95, 2646-2656.

57136.

572 Ives, A. R. \& Carpenter, S. R. (2007). Stability and diversity of ecosystems. Science, 317, 58-62.

57337.

574 Ives, A. R., Einarsson, A., Jansen, V. A. A. \& Gardarsson, A. (2008). High-amplitude fluctuations 575 and alternative dynamical states of midges in Lake Myvatn. Nature, 452, 84-87.

57638.

577 Ives, A. R., Abbott, K. C. \& Ziebarth, N. L. (2010). Analysis of ecological time series with 578 ARMA(p,q) models. Ecology, 91, 858-871.

57939.

580 Kéfi, S., Berlow, E. L., Wieters, E. A., Navarrete, S. A., Petchey, O. L., Wood, S. A. et al. (2012).

581 More than a meal... integrating non-feeding interactions into food webs. Ecol. Lett., 15, 291-300.

58240.

583 Klausmeier, C. A. (2008). Floquet theory: a useful tool for understanding nonequilibrium dynamics.

584 Theor. Ecol., 1, 153-161. 
58541.

586 Lloyd, A. L. \& Jansen, V. A. A. (2004). Spatiotemporal dynamics of epidemics: synchrony in 587 metapopulation models. Math. Biosci., 188, 1-16.

58842.

589 Loreau, M. (1994). Material cycling and the stability of ecosystems. Am. Nat., 143, 508-513.

59043.

591 Loreau, M. \& de Mazancourt, C. (2013). Biodiversity and ecosystem stability: a synthesis of 592 underlying mechanisms. Ecol. Lett., 16, 106-115.

59344.

594 Loreau, M., Naeem, S., Inchausti, P., Bengtsson, J., Grime, J. P., Hector, A. et al. (2001).

595 Biodiversity and ecosystem functioning: current knowledge and future challenges. Science, 294, $596 \quad 804-808$.

59745.

598 Lu, Y., Nakicenovic, N., Visbeck, M. \& Stevance, A.-S. (2015). Policy: Five priorities for the UN

599 Sustainable Development Goals. Nature, 520, 432-433.

60046.

601 MacDougall, A. S., McCann, K. S., Gellner, G. \& Turkington, R. (2013). Diversity loss with

602 persistent human disturbance increases vulnerability to ecosystem collapse. Nature, 494, 86-89.

60347.

604 Mace, G. M. (2014). Whose conservation? Science, 345, 1558-1560.

60548

606 Mace, G. M., Reyers, B., Alkemade, R., Biggs, R., Chapin III, F. S., Cornell, S. E. et al. (2014).

607 Approaches to defining a planetary boundary for biodiversity. Glob. Environ. Chang. 28, 289-297.

60849.

609 May, R. M. (1972). Will a large complex system be stable? Nature, 238, 413-414.

$610 \quad 50$. 
611 McCann, K. S. (2000). The diversity-stability debate. Nature, 405, 228-233.

61251.

613 McCann, K. S. \& Rooney, N. (2009). The more food webs change, the more they stay the same.

614 Philos. Trans. R. Soc. B-Biol. Sci., 364, 1789-1801.

61552.

616 Miller, A. D., Roxburgh, S. H. \& Shea, K. (2011). How frequency and intensity shape diversity-

617 disturbance relationships. Proc. Natl. Acad. Sci. U.S.A., 108, 5643-5648.

61853.

619 Montoya, J. M., Pimm, S. L. \& Solé, R. V. (2006). Ecological networks and their fragility. Nature, $620 \quad 442,259-264$.

62154.

622 Mrowicki, R.J., O'Connor, N.E. \& Donohue, I. (2016) Temporal variability of a single population 623 can determine the vulnerability of communities to perturbations. Journal of Ecology, 104, 887-897. 62455.

625 Naeem, S., Ingram, J. C., Varga, A., Agardy, T., Barten, P., Bennett, G. et al. (2015). Get the 626 science right when paying for nature's services. Science, 347, 1206-1207.

62756.

628 O'Connor, N. E. \& Donohue, I. (2013). Environmental context determines multi-trophic effects of 629 consumer species loss. Glob Chang Biol., 19, 431-440.

$630 \quad 57$.

631 O'Connor, N. E., Bracken, M. E. S., Crowe, T. P. \& Donohue, I. (2015). Nutrient enrichment alters 632 the consequences of species loss. J. Ecol., 103, 862-870.

63358

634 O'Gorman, E. J. \& Emmerson, M. C. (2009). Perturbations to trophic interactions and the stability 635 of complex food webs. Proc. Natl. Acad. Sci. U.S.A., 106, 13393-13398.

63659. 
637 OECD (2001). Governance in the 21st Century. OECD Publications.

63860.

639 Okuyama, T. \& Holland, J. (2008). Network structural properties mediate the stability of

640 mutualistic communities. Ecol. Lett., 11, 208-216.

64161.

642 Peters, D. P. C., Lugo, A. E., Chapin, F. S., Pickett, S. T. A., Duniway, M., Rocha, A. V. et al.

643 (2011). Cross-system comparisons elucidate disturbance complexities and generalities. Ecosphere, $644 \quad 2,1-26$

64562.

646 Pimm, S. L. (1982). Food Webs. The University of Chicago Press.

64763.

648 Pimm, S. L. (1984). The complexity and stability of ecosystems. Nature, 307, 321-326.

64964.

650 Pimm, S. L. (1991). The balance of nature?: ecological issues in the conservation of species and

651 communities. The University of Chicago Press.

65265.

653 Pimm, S. L. \& Lawton, J. H. (1977). Number of trophic levels in ecological communities. Nature, $654268,329-331$.

65566.

656 Pimm, S. L., Russell, G. J., Gittleman, J. L. \& Brooks, T. M. (1995). The future of biodiversity.

657 Science, 269, 347-350.

65867.

659 Pimm, S. L., Jenkins, C. N., Abell, R., Brooks, T. M., Gittleman, J. L., Joppa, L. N. et al. (2014).

660 The biodiversity of species and their rates of extinction, distribution, and protection. Science, 344, $661 \quad 1246752$.

66268. 
663 Pincebourde, S., Sanford, E., Casas, J. \& Helmuth, B. (2012). Temporal coincidence of

664 environmental stress events modulates predation rates. Ecol. Lett., 15, 680-688.

66569.

666 Quinlan, A. E., Berbés-Blázquez, M., Haider, L. J. \& Peterson, G. D. (2016). Measuring and 667 assessing resilience: broadening understanding through multiple disciplinary perspectives. $J$. Appl. 668 Ecol., 53, 677-687.

66970.

670 Rockström, J., Steffen, W., Noone, K., Persson, A., Chapin, F. S., Lambin, E. F. et al. (2009). A

671 safe operating space for humanity. Nature, 461, 472-475.

67271.

673 Rohr, R. P., Saavedra, S. \& Bascompte, J. (2014). On the structural stability of mutualistic systems.

674 Science, 345, 416.

67572.

676 Ruokolainen, L. \& Fowler, M. S. (2008). Community extinction patterns in coloured environments.

677 Proc. R. Soc. B., 275, 1775-1783.

67873.

679 Scheiner, S. M. (2013). The ecological literature, an idea-free distribution. Ecol. Lett., 16, 14216801423.

68174.

682 Shou, W., Bergstrom, C. T., Chakraborty, A. K. \& Skinner, F. K. (2015). Theory, models and 683 biology. eLife, 4, e07158.

68475.

685 Solé, R. V. \& Montoya, J. M. (2001). Complexity and fragility in ecological networks. Proc. R. 686 Soc. B., 268, 2039-2045.

$687 \quad 76$. 
688 Sousa, W. P. (1984). The role of disturbance in natural communities. Annu. Rev. Ecol. Evol. Syst., $689 \quad 15,353-391$.

69077.

691 Staniczenko, P. P. A., Lewis, O. T., Jones, N. S. \& Reed-Tsochas, F. (2010). Structural dynamics 692 and robustness of food webs. Ecol. Lett., 13, 891-899.

69378.

694 Steffen, W., Richardson, K., Rockström, J., Cornell, S. E., Fetzer, I., Bennett, E. M. et al. (2015).

695 Planetary boundaries: Guiding human development on a changing planet. Science, 347, 1259855.

69679.

697 Stenseth, N. C., Durant, J. M., Fowler, M. S., Matthysen, E., Adriaensen, F., Jonzén, N. et al.

698 (2015). Testing for effects of climate change on competitive relationships and coexistence between 699 two bird species. Proc. R. Soc. B, 282, 20141958.

70080.

701 Stockholm Resilience Centre (2012). Planetary Boundaries: Addressing some key misconceptions. 702 Available at: http://www.stockholmresilience.org/21/research/research-news/7-2-2012-addressing703 some-key-misconceptions.html. Last accessed 30 August 2015.

70481.

705 Suweis, S., Simini, F., Banavar, J. \& Maritan, A. (2013). Emergence of structural and dynamical 706 properties of ecological mutualistic networks. Nature, 500, 449-452.

70782.

708 Tallis, H., Mooney, H., Andelman, S., Balvanera, P., Cramer, W., Karp, D. et al. (2012). A global 709 system for monitoring ecosystem service change. Bioscience, 62, 977-986.

71083.

711 Tamburello, L., Bulleri, F., Bertocci, I., Maggi, E. \& Benedetti-Cecchi, L. (2013). Reddened 712 seascapes: experimentally induced shifts in $1 / \mathrm{f}$ spectra of spatial variability in rocky intertidal 713 assemblages. Ecology, 94, 1102-1111. 
71484.

715 TEEB (2010). The Economics of Ecosystems and Biodiversity: Mainstreaming the Economics of

716 Nature: A Synthesis of the Approach, Conclusions and Recommendations of TEEB.

71785.

718 Thébault, E. \& Fontaine, C. (2010). Stability of ecological communities and the architecture of

719 mutualistic and trophic networks. Science, 329, 853-856.

72086.

721 Tilman, D., Reich, P. B. \& Knops, J. M. H. (2006). Biodiversity and ecosystem stability in a

722 decade-long grassland experiment. Nature, 441, 629-632.

72387.

724 Tilman, D., Reich, P. B. \& Isbell, F. (2012). Biodiversity impacts ecosystem productivity as much 725 as resources, disturbance, or herbivory. Proc. Natl. Acad. Sci. U.S.A., 109, 10394-10397.

72688.

727 Tylianakis, J. M., Didham, R. K., Bascompte, J. \& Wardle, D. A. (2008). Global change and

728 species interactions in terrestrial ecosystems. Ecol. Lett., 11, 1351-1363.

72989.

730 UN (1992). Text of the CBD. Available at: https://www.cbd.int/convention/text/. Last accessed 30

731 August 2015.

73290.

733 UN (2008). UN Collaborative Programme on Reducing Emissions from Deforestation and Forest

734 Degradation in Developing Countries (UN-REDD). FAO, UNDP, UNEP Framework Document.

73591.

736 UN (2010). Aichi Biodiversity Targets. Available at: https://www.cbd.int/sp/targets/. Last accessed

$737 \quad 30$ August 2015.

73892. 
739 van Nes, E. H. \& Scheffer, M. (2004). Large species shifts triggered by small forces. Am. Nat., 164, $740 \quad 255-266$.

74193.

742 Walker, B., Holling, C. S., Carpenter, S. R. \& Kinzig, A. (2004). Resilience, adaptability and

743 transformability in social-ecological systems. Ecol. Soc., 9, 5.

74494.

745 Zavaleta, E., Pasari, J., Hulvey, K. \& Tilman, G. (2010) Sustaining multiple ecosystem functions in 746 grassland communities requires higher biodiversity. Proc. Natl. Acad. Sci. U.S.A., 107, 1443-1446. 
747 Table 1. International agreements, organisations and agencies whose policy targets and mission and vision statements we searched for terms associated

748 with ecological stability.

\begin{tabular}{|c|c|c|}
\hline Entity & $\begin{array}{l}\text { Stability related term(s) } \\
\text { found }\end{array}$ & Document link \\
\hline
\end{tabular}

Aichi biodiversity targets (CBD)

Biodiversity International

Birdlife International

Convention on Biological Diversity

Conservation International

UK Department for Environment, Food \& Rural Affairs

Diversitas (now rolled into Future Earth)

Earthwatch

European Environment Agency

European Platform for Biodiversity Research

Strategy

Earth System Science Partnership

European Union Biodiversity Observation

Network

Food and Agriculture Organisation

Future Earth

Global Environment Facility

GreenPeace

International Association for Landscape

Ecology

Intergovernmental platform on biodiversity and ecosystem services

Intergovernmental Panel on Climate Change

International tropical timber organisation

International Union for Conservation of

Nature

LifeWatch infrastructure for biodiversity and

ecosystem research 'integrity'; 'safe ecological

limits'; 'resilience'; 'sustain';

'conserve'

'sustain'; 'safeguard'

'sustain'; 'maintain'

'sustain'; 'conserve'

'healthy'; 'sustainable';

'stable'

'safeguard'

'secure'; 'conserve'; 'sustain'

'sustain'

'sustainable'

'maintain'; 'sustain';

'conserve'

'sustainable'

None found

'security'; 'sustainable

'sustainable'

'sustainable'

'protect'

'altered'

'conserve'; sustain'

None found

'sustainable'; 'conservation'

'conserve'; 'sustain'

None found http://www.cbd.int/sp/targets/

http://www.bioversityinternational.org/about-us/who-we-are/

http://www.birdlife.org/worldwide/partnership/our-vision-mission-and-commitment

http://www.cbd.int/convention/articles/default.shtml? $\mathrm{a}=$ cbd-01

http://www.conservation.org/about/Pages/default.aspx\#mission

https://www.gov.uk/government/organisations/department-for-environment-food-rural-affairs/about

http://www.diversitas-international.org/about/mission-and-history

http://eu.earthwatch.org/about/earthwatch-mission-and-values

http://www.eea.europa.eu/about-us

http://www.epbrs.org

http://www.essp.org

http://www.eubon.eu/show/project_2731/

http://www.fao.org/about/en/

http://www.futureearth.org

https://www.thegef.org/gef/whatisgef

$\mathrm{http}: / / \mathrm{www}$.greenpeace.org/international/en/about/our-core-values/

http://www.landscape-ecology.org/index.php?id=14

http://dx.doi.org/10.1016/j.cosust.2014.11.002

http://www.ipcc.ch/organization/organization.shtml

http://www.itto.int/about_itto/

http://www.iucn.org

http://www.lifewatch.eu 
Living with Environmental Change

Natural Capital Project

Organisation for Economic Co-operation and

Development

Rainforest Alliance

The Economics of Ecosystems and

Biodiversity

The Nature Conservancy

United Nations Reducing Emissions from

Deforestation and Forest Degradation

United Nations Convention to Combat

Desertification

United Nations Environment Programme

Kyoto protocol (UNFCCC)

United Nations Sustainable Development

Goals

Wetlands International

World Meteorological Organisation

World Nature Organisation

Stern Review on the Economics of Climate

Change

Worldwatch Institute

World Wildlife Fund for Nature

York Environment Sustainability Institute

Convention on International Trade in

Endangered Species of Wild Fauna and Flora

International Whaling Commission
None found

'sustainable'

'sustainable'; 'resilience'

'conserve'; 'sustain';

'safeguard'

None found

'conserve'

'constrain impacts'

'sustain'; 'secure'

'sustain'

'stabilise'

'security'; 'sustainable';

'resilient'; 'conserve'; 'protect'

'resilience'

'safety'

'sustainable'

None found

'sustainable'

'harmony'; 'safeguard'

'resilient'; 'maintain';

'conservation'

'survival'

'conservation' http://www.lwec.org.uk/about

http://www.naturalcapitalproject.org

http://www.oecd.org/env/

http://www.rainforest-alliance.org/about

http://www.teebweb.org/about/

http://www.nature.org/about-us/vision-mission/index.htm?intc=nature.tnav.about.list http://www.un-redd.org

http://www.unccd.int/en/Pages/default.aspx

http://www.unep.org/Documents.Multilingual/Default.asp?DocumentID=43

http://unfccc.int/kyoto_protocol/items/2830.php

https://sustainabledevelopment.un.org/post2015/transformingourworld

http://www.wetlands.org/Aboutus/VisionMission/tabid/58/Default.aspx

https://www.wmo.int/pages/about/mission en.html

http://www.wno.org/mission

http://mudancasclimaticas.cptec.inpe.br/ rmclima/pdfs/destaques/sternreview_report_complete.pdf

http://www.worldwatch.org/mission

http://wwf.panda.org/wwf_quick_facts.cfm

http://www.york.ac.uk/media/yesi/downloaddocuments/YESI\%20Brochure-WEB.pdf

http://www.cites.org/eng/disc/what.php

https://iwc.int/history-and-purpose 
750 Table 2. Stability-like terms used in policy targets and mission and vision statements of the international agreements, organisations and agencies

751 highlighted in Table 1, ranked in order of frequency of occurrence, and the components of stability that they associate with in the context of their use.

752 The use of resistance here incorporates robustness. We assume that the necessity for systems to be asymptotically stable around an equilibrium point or

753 limit cycle is implicit in the use of every term.

754

\begin{tabular}{llll} 
Terms used in policy & Occurrence & $\begin{array}{l}\text { Stability component(s) associated most } \\
\text { strongly }\end{array}$ & Other associated stability components \\
\hline & & & \\
'sustain'/'sustainable' & $25 / 42$ & Persistence & Resistance, Resilience, Variability \\
'conserve'/'conservation' & $13 / 42$ & Persistence & Resistance, Resilience \\
'resilience'/'resilient' & $5 / 42$ & Resistance & Resilience, Persistence \\
'safeguard' & $4 / 42$ & Persistence & Resistance \\
'maintain' & $3 / 42$ & Persistence & Resistance, Variability \\
'secure'/'security' & $4 / 42$ & Persistence & Resistance, Resilience \\
'stabilise'/'stable' & $2 / 42$ & Variability & Resistance, Resilience, Persistence \\
'protect' & $2 / 42$ & Persistence & Resistance \\
'altered' & $1 / 42$ & Persistence & Resistance \\
'constrain impacts' & $1 / 42$ & Resistance & Resilience \\
'harmony' & $1 / 42$ & Variability & Resilience \\
'healthy' & $1 / 42$ & Resistance & Persistence, Resilience \\
'integrity' & $1 / 42$ & Resistance & Persistence \\
'safety' & $1 / 42$ & Resistance & Resistance, Resilience \\
'survival' & $1 / 42$ & Persistence & Persistence, Resilience, Variability, \\
'safe ecological limits' & $1 / 42$ & Resistance & Multiple locally stable equilibria \\
\end{tabular}


758 Fig. 1. Conceptual summary of multifaceted disturbances. Characterisation of pure pulse and press disturbances (a) that are the focus of most theoretical and experimental studies, and an intermediate multiple pulse form of disturbance (dotted blue line) that is also studied frequently, mostly in the form of natural environmental fluctuations in observational studies. Most disturbances are, however, neither pulse nor press and instead change in magnitude over time (b), frequently with shifting mean and variance components. We lack theory and have very limited empirical evidence on the impacts of these directional aspects of disturbances on ecological stability, yet they represent many of the most important and widespread aspects of human impacts (c).

Fig. 2. The restricted focus of studies on single components of stability (a) and disturbances (b). The total number of studies is slightly lower in (b) because some of the studies we surveyed did not incorporate an explicit disturbance.

Fig. 3. Overview of studies of ecological stability. Number of studies identified by our survey of the literature that quantified different facets of stability (a), examined the effects of different components of disturbance on those (b), and that used biomass, taxonomic composition or ecosystem functioning as a basis for measuring stability (c).

Fig. 4. Integrating across multiple dimensions to quantify overall ecological stability. We suggest a method that incorporates multiple stability facets and allows for their differential weighting. This method is based loosely on one developed for the assessment of biodiversity effects on multiple ecosystem functions (Byrnes et al. 2014). A multiple-criteria decision781 making approach would also be suitable here. First, the method identifies which stability 
782 facets can be quantified and provides a scoring system for each facet (a). This could be as 783 simple as low, moderate and high, although more sophisticated scoring systems could be 784 developed. It then applies a weighting factor to each score, depending on their perceived 785 relative importance for a given policy or management practice (b). The sum of the weighted 786 scores then corresponds to the stakeholder's value of the stability of the system (c). Even 787 though different facets of stability may be correlated, there is no need to assume this. Trade788 offs and synergies among stability metrics can be incorporated, but the method does not 789 assume dependencies. 


\section{Box 1: Why the attempt to define planetary boundaries is flawed}

Human actions are changing the biosphere in unprecedented ways. One view is that, given the magnitude and novelty of these impacts, there will be thresholds, beyond which abrupt non-linear change will bring the biosphere to a new and undesirable equilibrium. This view of nature, founded upon Holling's (1973) definition of resilience, explicitly engages policymakers with its invocation of catastrophic tipping points and the conclusion that Earth has already exceeded them. The view is becoming increasingly pervasive in the scientific literature.

Certainly, there may be systems that show the tipping points that underpin this worldview. Importantly, there is nothing to suggest they are ubiquitous and so demand their having logical primacy. Nature might work this way sometimes, but there is no compelling argument that it must. In attempting to define global tipping points and, from those, "planetary boundaries", Rockström et al. (2009) have extended this view to circumstances where it is unlikely to operate. We take as an example the variable they deemed already to be outside the planetary boundary arising from our work (Pimm et al. 1995; Pimm et al. 2014): the rate of species extinctions. The metric is simple - a fraction of species going extinct per unit time. The comparison to a natural background rate is also conceptually easy, though there are practical difficulties (De Vos et al. 2015). The notion that the current global species extinction rate - about a thousand times higher than background — has exceeded some tipping point where catastrophic ecological changes must follow is problematical in several ways (Mace et al. 2014).

First, it is not clear over what spatial and temporal scales extinction rates have exceeded the boundary. For example, how are the locally high rates of plant and animal extinctions on remote Pacific Islands following first contact with Polynesians and later with Europeans supposed to "tip" processes globally or (say) in the Amazon? And over what time period might these catastrophic changes unfold?

Subsequent clarifications by Rockström and colleagues (Stockholm Resilience Centre 2012; Steffen et al. 2015) indicate that the proposed 'planetary' boundary for extinctions operates at 
816 regional scales, but they are not explicit in defining either the spatial or temporal extents of these

817 regions. This leaves open the vitally important question for policymakers of what scales are most 818 important.

819 Second, there are models of the consequences of losing species and how many more species 820 will be lost consequently at local and regional scales (Pimm 1991). None shows the kind of 821 runaway processes that Rockström and colleagues imagine. Certainly, there is both an extensive 822 theoretical and empirical literature on how species richness (as opposed to its rate of change) affects 823 a variety of ecosystem functions including primary productivity and nutrient cycling (Loreau et al. 824 2001; Cardinale et al. 2012). This literature shows degradation as species numbers decline 825 (Cardinale et al. 2011), but no clear thresholds. 


\section{Box 2: Learning from experience: biodiversity-ecosystem functioning and service provision}

Even when theoreticians and empiricists converge in what they quantify, there is no guarantee of immediate and successful translation into the policy and management arena. Research on Biodiversity-Ecosystem Functioning (BEF) and Biodiversity-Ecosystem Services (BES) relationships exemplifies this and, as such, we can learn from it.

A large body of experiments (> 600 since 1990) developed in close relation with mathematical theory and showed how genetic, species and functional diversity of organisms regulate basic ecological processes - functions - in ecosystems (Cardinale et al. 2012). As a result, there is now unequivocal evidence supported by theory that biodiversity loss reduces biomass production, decomposition and recycling of essential nutrients, and the efficiency at which ecosystems capture biological resources. In parallel, a strong policy impulse developed trying to guarantee the provision of ecosystem services to society, now under the umbrella of the recently established Intergovernmental Science-Policy Platform on Biodiversity and Ecosystem Services (IPBES; Díaz et al. 2015). Despite the mechanistic understanding of the effects of biodiversity on functioning provided by theoreticians and empiricists, the mechanistic links between biodiversity and ecosystem services are far from being established. This disconnect effectively impairs the distillation of conclusions to inform policy on how biodiversity loss will affect service provisioning and regulation and, ultimately, human wellbeing.

An example is Payment for Ecosystem Services (PES), where beneficiaries of nature's services pay owners or stewards of ecosystems that generate those services. Naeem et al. (2015) suggested recently that few PES studies get the science right, with most projects based on weak scientific foundations. The main reason for this was poor interdisciplinary communication and coordination. The absence of unifying definitions and associated metrics, baseline data, monitoring, recognition of the dynamic nature of ecosystems, and poor interdisciplinary communication and coordination helps to explain this gap. The BEF community measures functions without linking those to known services. The BES community commonly describe services without linking them to 
852 their underlying ecological function. A more active communication and convergence on what to

853 measure and at what scale, and how to monitor over space and time is needed (Cardinale et al.

854 2012; Naeem et al. 2015). 

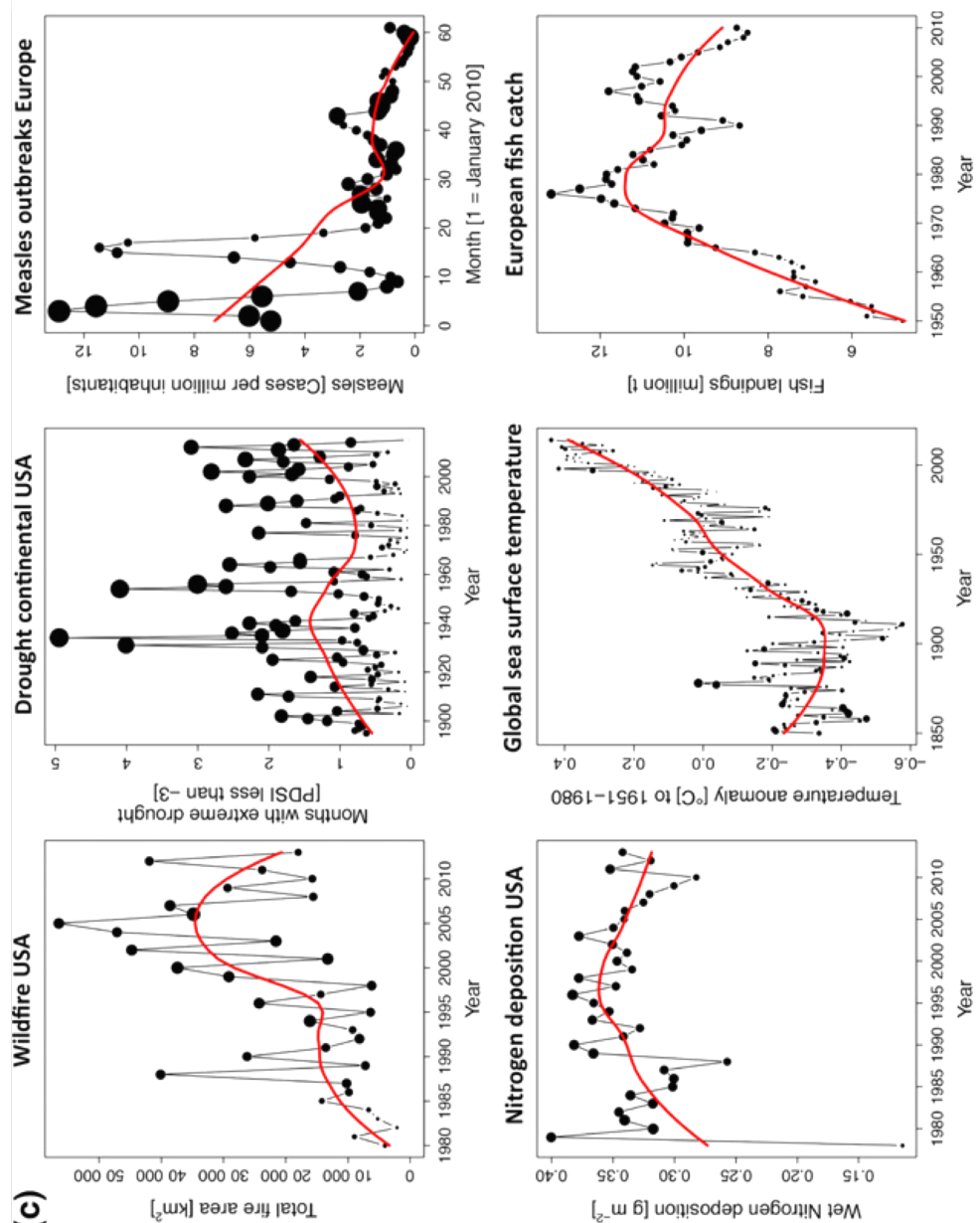

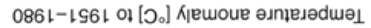
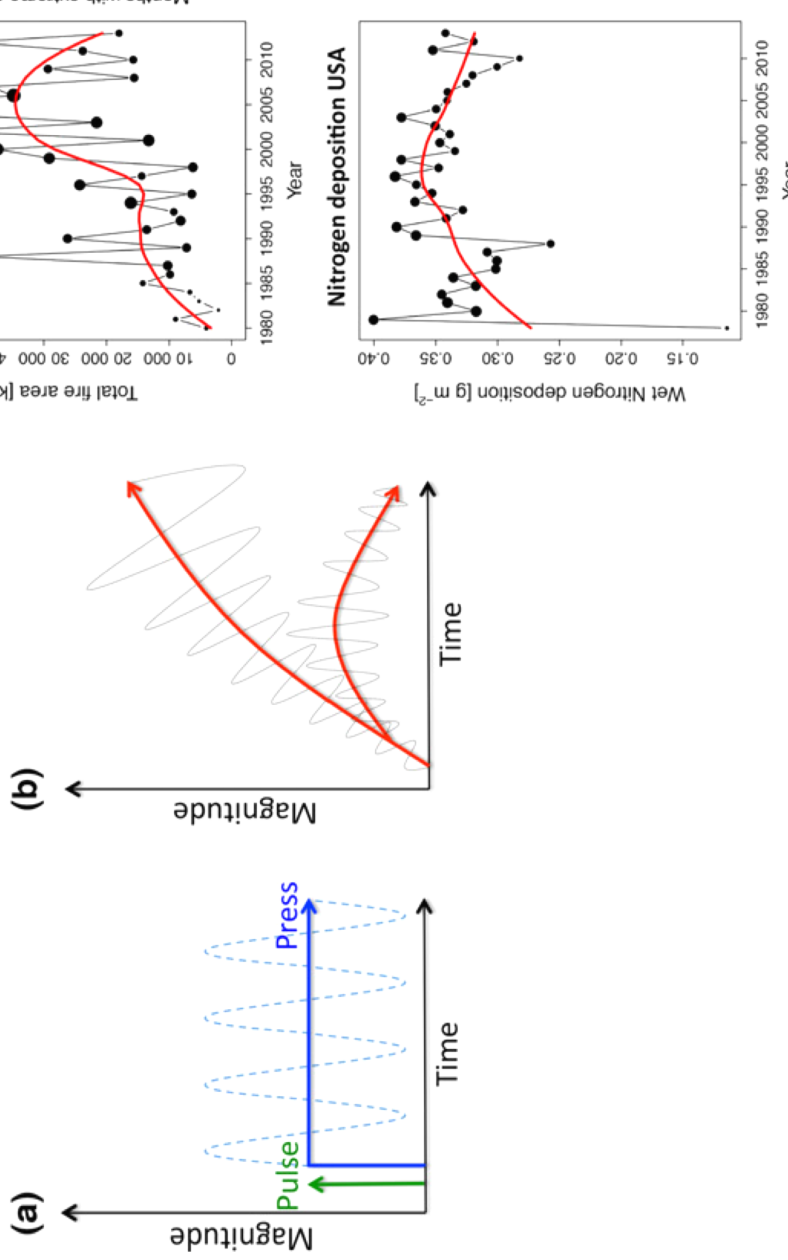
- Studies combining theory and an empirical component m Observational studies $\equiv$ Experimental studies $\approx$ Theoretical studies

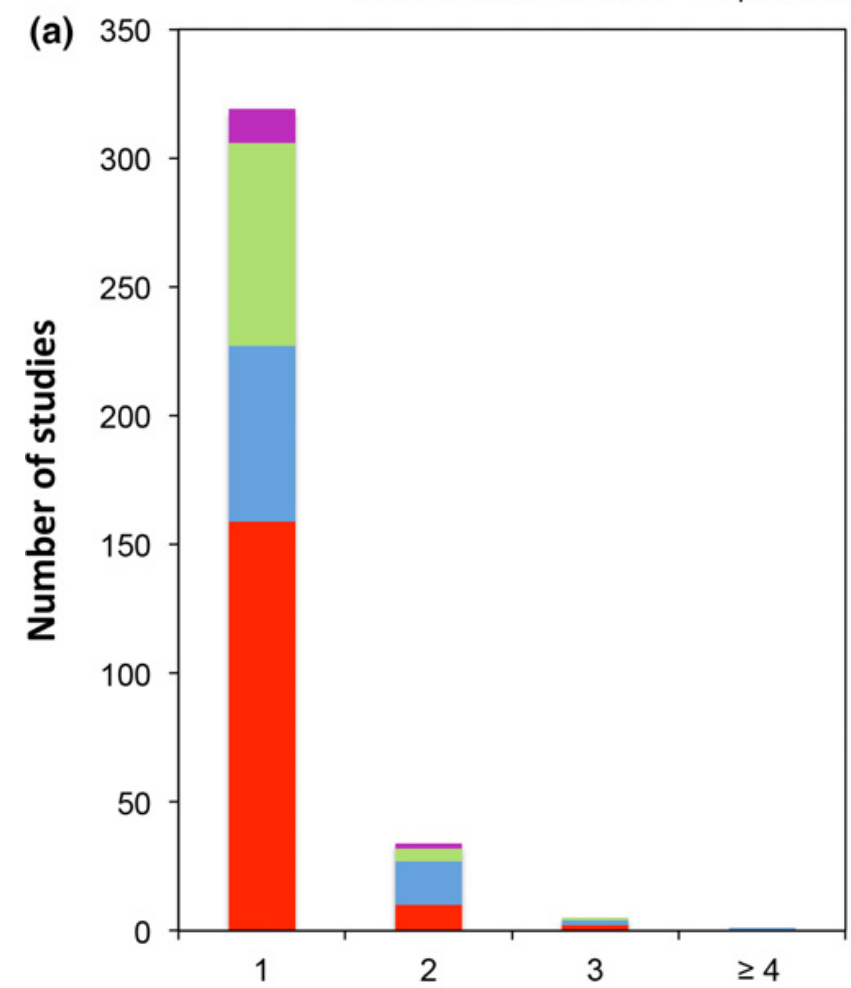

Number of stability components measured

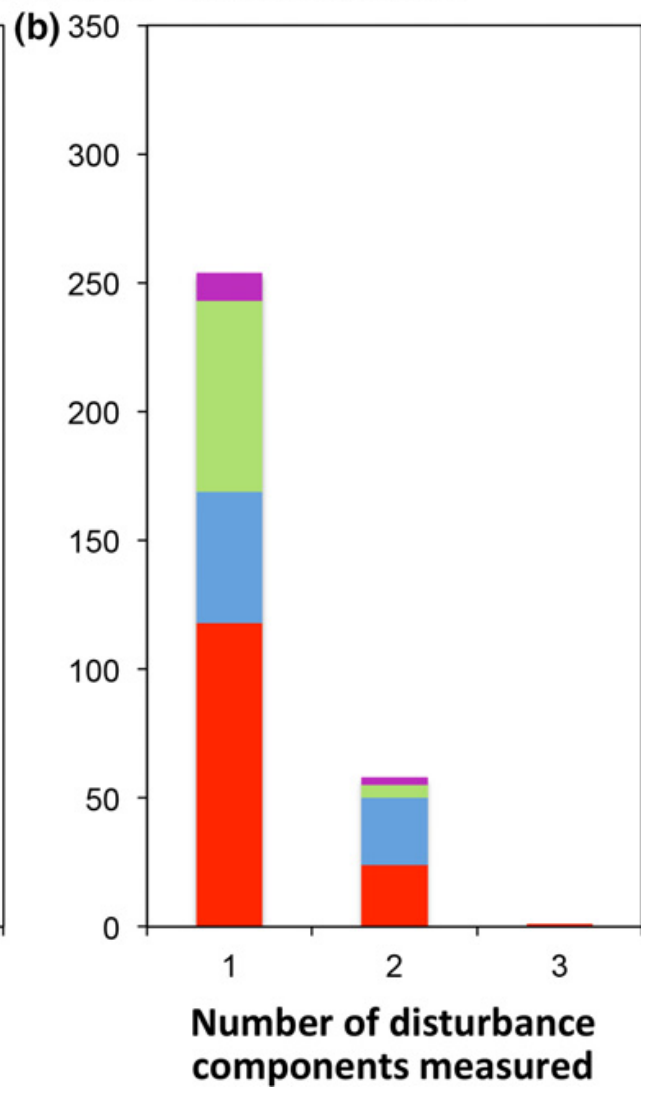

Figure 2 
- Studies combining theory and an empirical component

m Observational studies $\square$ Experimental studies $\backsim$ Theoretical studies

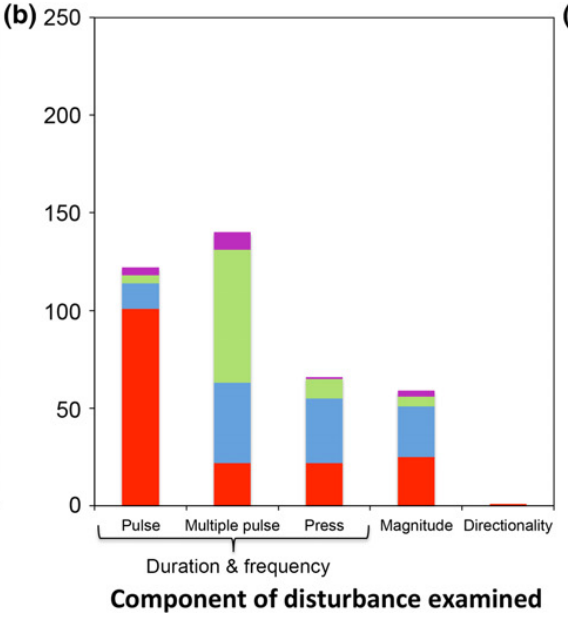

863

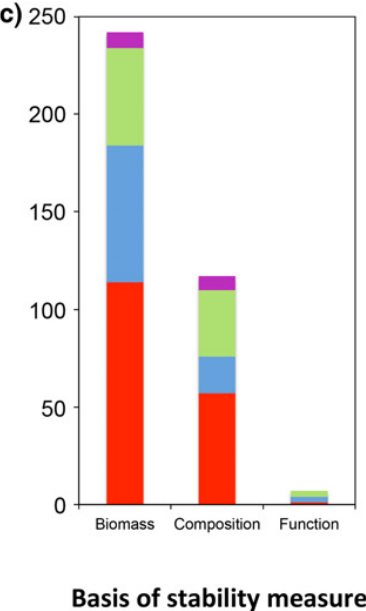

Figure 3 


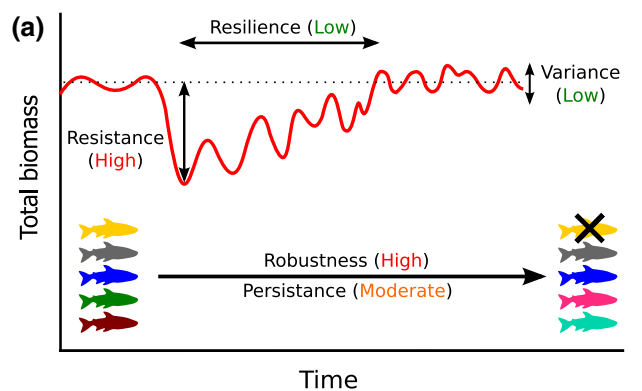

(b)

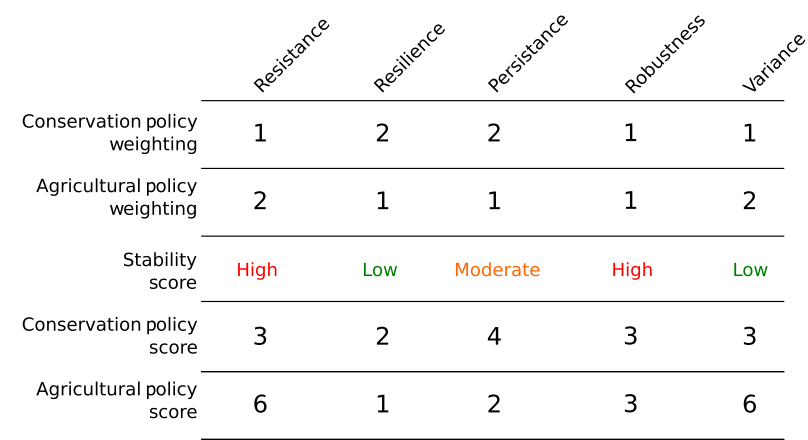

(c)

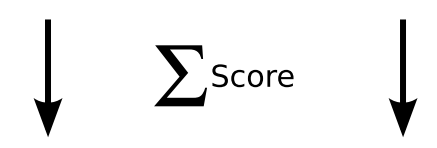

865

866

867

868

\begin{tabular}{lll} 
& \multicolumn{2}{c}{ Conservation policy } \\
Overall total score & 15 & Agricultural policy \\
&
\end{tabular}
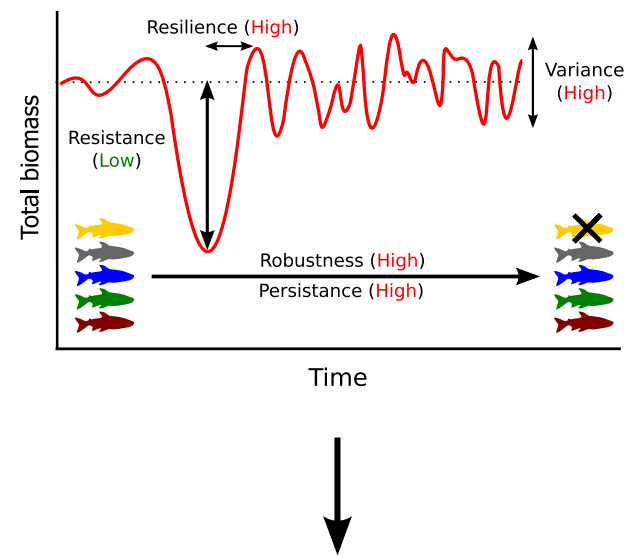

\begin{tabular}{|c|c|c|c|c|c|}
\hline $\begin{array}{r}\text { Conservation policy } \\
\text { weighting }\end{array}$ & 1 & 2 & 2 & 1 & 1 \\
\hline $\begin{array}{r}\text { Agricultural policy } \\
\text { weighting }\end{array}$ & 2 & 1 & 1 & 1 & 2 \\
\hline $\begin{array}{r}\text { Stability } \\
\text { score }\end{array}$ & Low & High & High & High & High \\
\hline $\begin{array}{r}\text { Conservation policy } \\
\text { score }\end{array}$ & 1 & 6 & 6 & 3 & 3 \\
\hline $\begin{array}{l}\text { Agricultural policy } \\
\text { score }\end{array}$ & 2 & 3 & 3 & 3 & 6 \\
\hline
\end{tabular}

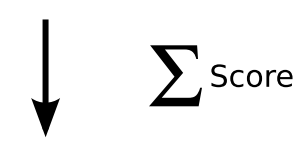

$\begin{array}{lcc} & \text { Conservation policy } & \text { Agricultural policy } \\ \text { Overall total score } & 19 & 17\end{array}$

(a) 
